\title{
Chondrosarcoma of the nasal septum
}

\author{
Mohammed Bahgat, ${ }^{1}$ Yassin Bahgat, ${ }^{1}$ Ahmed Bahgat, ${ }^{1}$ Yasmine Elwany ${ }^{2}$ \\ ${ }^{1}$ Department of ENT and Head \& Neck Surgery, Alexandria University Hospitals, Alexandria, Egypt \\ ${ }^{2}$ Department of Oncology, Alexandria University Hospitals, Alexandria, Egypt
}

Correspondence to Dr Mohammed Bahgat, mybahgat18@hotmail.com

\section{Summary}

Chondrosarcoma of the nasal septum is a rare malignancy. When it occurs, early diagnosis is difficult because patients generally present with common, non-specific sinonasal complaints. This is the report of a 62-year-old woman who presented with a 1-month history of nasal obstruction, headache and anosmia. Nasal endoscopy showed a nasal mass obstructing both nasal cavities not separable from the septum. A wedge biopsy of the nasal mass was taken. Histopathology was suggestive of chondrosarcoma. The tumour was removed by an endoscopic approach. The clinical presentation, diagnosis and treatment of this case as well as a review of the literature are discussed.

\section{BACKGROUND}

Chondrosarcomas arise in tissues known to be formed of cartilage. Chondrosarcomas are rare tumours and approximately $5-10 \%$ are located in the head and neck region. ${ }^{1}$ The nasal septum is a particularly rare site of origin of this tumour. ${ }^{2}$ It is a slow-growing tumour, occurring mostly in middle-aged men. Primary chondrosarcoma of the nasal and paranasal sinus region, including the nasal septum, rarely extends into the cranial or intracranial areas unless there is recurrence. ${ }^{3}$

\section{CASE PRESENTATION}

A 62-year-old woman presented in January 2011 with a 1-month history of nasal obstruction, persistent headache and anosmia. The patient did not report any episode of nasal bleeding. There was no history of loss of vision, diplopia, proptosis, facial pain, facial swelling, fever or weight loss.

No history of tuberculosis or diabetes mellitus was evident. There was no history of a similar condition in her family.

Nasal endoscopy revealed the presence of a firm, smooth, fleshy and non-tender intranasal mass occupying both nasal cavities (figure 1). The mass was not separable from the nasal septum on probing. No bleeding occurred on touching. The nasopharynx appeared normal with patent Eustachian tube on both sides.

Intraorally, there was no bulge over the hard palate, which was covered by normal mucosa. Otoscopy was normal with no middle-ear effusion, and her hearing was normal. Her ocular movements were normal with no diplopia. There were no palpable lymph nodes. Her general and systemic examinations were normal. The patient had only persistent headache but no symptoms of increased intracranial pressure; neurological examination was normal.

\section{INVESTIGATIONS}

Both CT and MRI were needed to fully evaluate the bone and soft-tissue characteristics of the lesion. The CT scan of the patient's paranasal sinuses showed about $4 \times 4.8 \times 4 \mathrm{~cm}$ intranasal mass with erosive changes of the nasal septum and calcified foci noted at the right aspect of the mass (figure 2).
Superiorly, erosion of the ethmoidal air cells was noted. Laterally, it implicated the middle turbinates on the right side with flaring and widening of the ostiomeatal units on both sides and complete opacification of both the maxillary and right frontal sinuses, and bony remodelling of the medial wall of the right orbit with focal cortical interruption. No skull base erosion was noted.

MRI techniques allowed a precise definition of the nature, extent and size of mass. The mass was shown to expand the right nasal cavity with intense marginal enhancements and also enhancement cement of internal septations and nodular components, with violation of the bony matrix of the right ethmoidal air cells and ipsilateral turbinates as well as violation of the bony matrix of the nasal septum and extension to the contralateral left nasal cavity compromising its patency. Impressive remodelling of the right lamina papyracea, but no intraorbital or intracranial extension, was noted (figure 3 ).

A wedge biopsy of the nasal mass was taken. Histopathology revealed lobules of chondromatous tissue and, at places, was lined by nasal mucosa. Few lobules were relatively acellular and resembled mature cartilage, whereas others showed marked increase in cellularity with large chondrocytes having enlarged multinucleated and binucleated cells. Histology of the specimen was suggestive of low-grade chondrosarcoma.

\section{DIFFERENTIAL DIAGNOSIS}

Differential diagnosis includes other malignant and benign tumours of the nasal cavity as squamous cell carcinoma, adenocarcinoma, adenoid cystic carcinoma, inverted papilloma, schwannoma, sinonasal melanoma, haemangioma, osteoma and chondroma. It is reported that differential diagnosis from chondroma is most difficult, and head and neck chondrosarcoma may be initially misdiagnosed as chondromas. ${ }^{4}$

Although rare, chondrosarcoma of the nasal septum should be considered in the differential diagnosis of persistent nasal obstruction as well. 


\section{BMJ Case Reports}
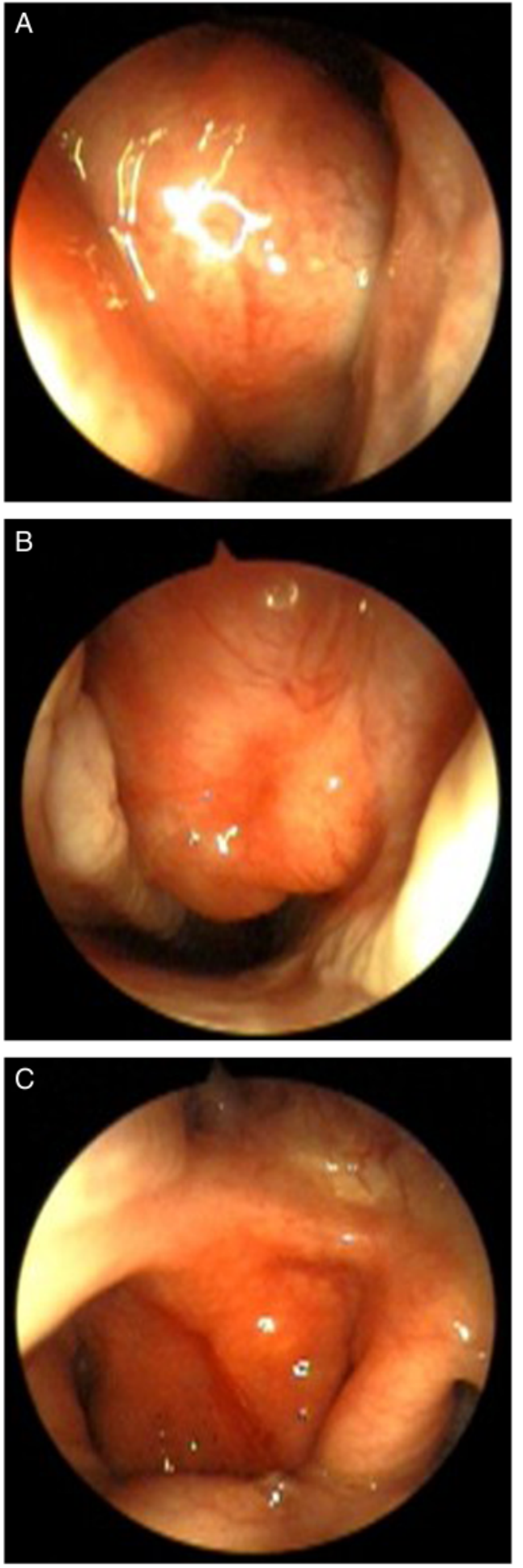

Figure 1 Nasal endoscopy showing the mass (arrow) with a smooth mucosa surface, occupying both nasal cavities, attached to the nasal septum on both sides $(A, B)$. The nasopharynx appears normal with patent Eustachian tubes (C). M, mass; IT, inferior turbinate; S, septum.

\section{TREATMENT}

After a meeting of the multidisciplinary team, the decision was taken to remove the tumour by an endoscopic approach under general anaesthesia, as the tumour was

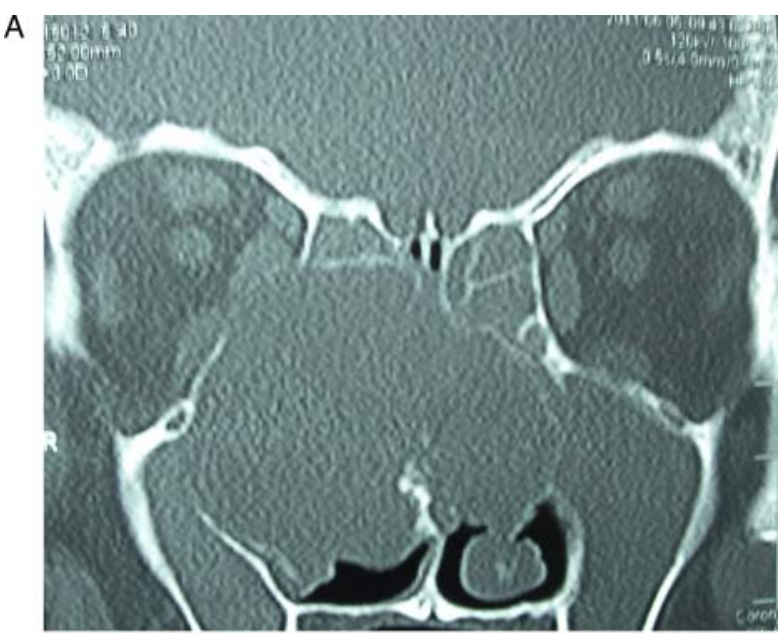

B

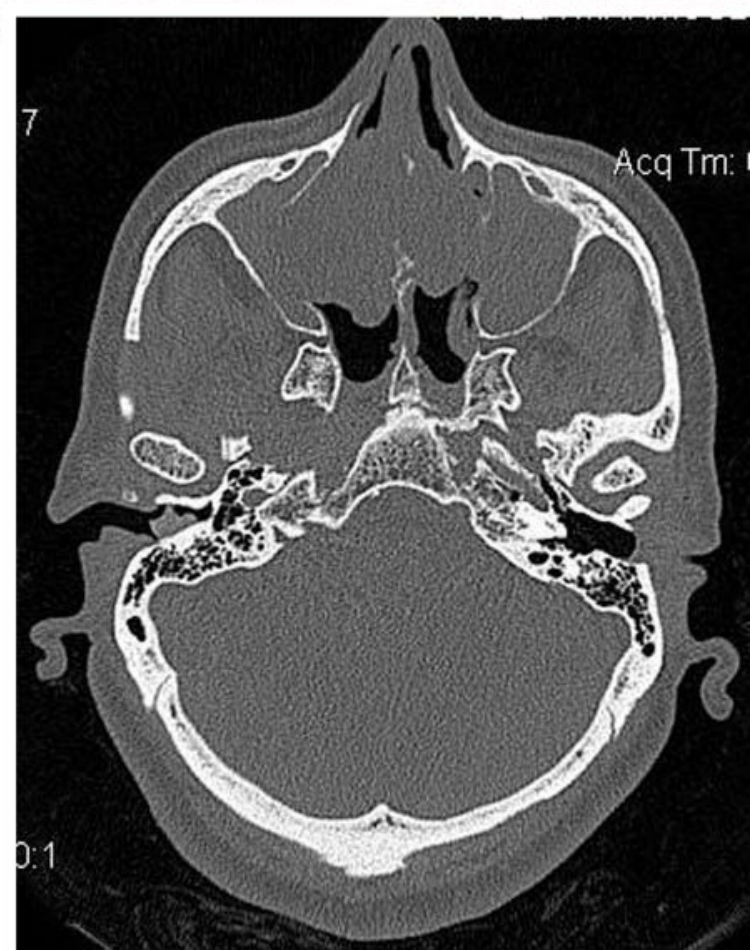

Figure 2 (A) CT (coronal) of the nasal cavity revealing a mass (arrow). The mass is adjacent to the skull base, but there is no clear bone defect or erosion. The maxillary sinuses are filled with fluid collection. (B) CT (axial) of the nasal cavity revealing a mass (arrow) occupying both nasal cavities.

fully visualised by endoscopic techniques. First, the tumour was separated from the posterior part of the nasal septum that was perforated. Then, the left nasal component of the mass was gradually dissected and separated from the middle turbinate, which was displaced laterally but not attached to the mass. The right nasal component of the mass involved the right middle turbinate and right ethmoidal lesion and was gradually dissected under endoscopic control with preservation of the lamina papyracea. Haemostasis was assured by bipolar diathermy and Surgicel packing. There were no findings of invasion into the skull base. The postoperative period was uneventful. Her vision and ocular movements were normal. Olfactory function improved postoperatively. No adjuvant treatment was given. 

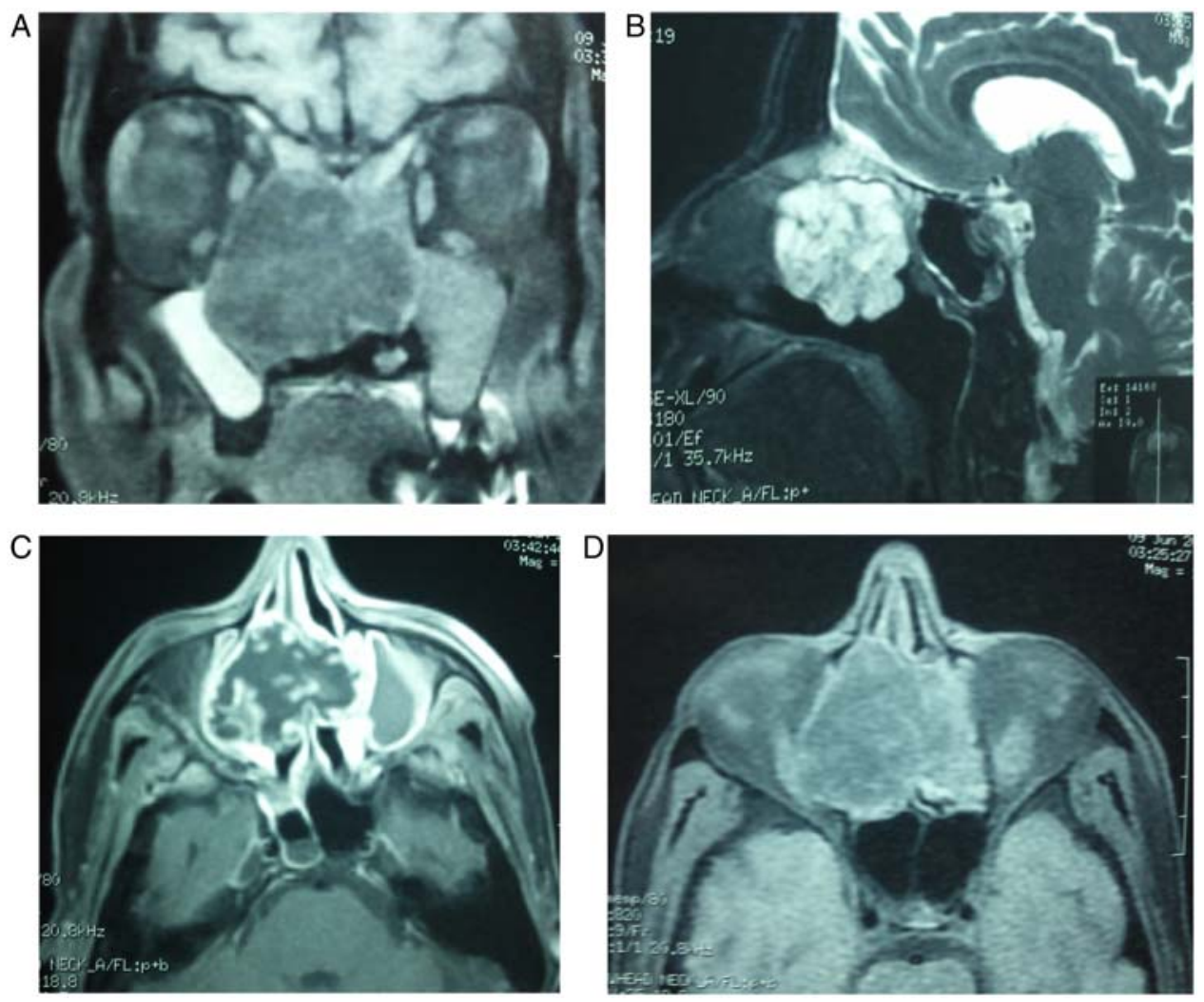

Figure 3 (A) Coronal, (B) sagittal and (C, D) axial MRI showing intranasal mass (arrow).

\section{OUTCOME AND FOLLOW-UP}

Follow-up nasal endoscopy and CT were done (figure 4). The patient remained free of disease clinically and radiologically at 1-year follow-up. Regular follow-up by endoscopy is mandatory.

\section{DISCUSSION}

Chondrosarcomas constitute an uncommon group of cartilaginous tumours. They comprise only $10-20 \%$ of all malignant primary bone tumours, of which only $10 \%$ arise from the head and neck areas. ${ }^{14}$ Hence, this malignancy is considered as one of the rarest and the origin of chondrosarcomas from the nasal septum is extremely rare. $^{2}{ }^{3}$ The usual age of presentation varies between 40 and 50 years, ${ }^{3}$ with higher incidence among men. ${ }^{3}$ Hence, this case of a woman presenting with a chondrosarcoma of the nasal septum is an unusual one.

Symptomatology varies according to the site and size of the tumour. Usually, nasal obstruction, nasal discharge, facial asymmetry, headache, restricted ocular movements, diplopia, proptosis, facial pain, anosmia and ear fullness are presenting symptoms. ${ }^{5}$ In this case, the patient did not have any symptoms other than nasal obstruction, anosmia and persistent headache.

Thorough clinical examination is important to reach full diagnosis. Nasal endoscopy shows the diseased mucosa and the mass. It provides information about the nasopharyngeal extension of the mass and the obstruction of the Eustachian tubes. Oral examination is important to detect invasion into the hard palate. Head and neck examination is a must to detect lymph node spread. Eye examination is important to detect intraorbital extension that can manifest as diplopia, proptosis, limited ocular movements or loss of vision. Ear examination is important to detect eustachian tube occlusion by the mass that can manifest as hearing loss due to middle-ear effusion. Neurological examination is important to detect intracranial extension.

Radiological imaging is essential before attempting surgical intervention. CT in the coronal and axial plain is the most informative investigation in evaluating the exact location of the tumour. ${ }^{15}$ Bony destruction and calcification with an isodense or hypodense non-enhancing mass are common findings of a CT scan. MRI provides better soft-tissue details and tissue characterisation and hence allows a precise definition of the nature, extent and size of tumour. MRI is important to detect intraorbital and intracranial extensions of the lesion. ${ }^{2} 56$

Wedge biopsy of the lesion is important. The diagnosis of chondrosarcomas is made by biopsy and histopathological examination. ${ }^{4} 6$

Chondrosarcoma is a radio-resistant tumour owing to its prolonged response time to radiation, so the standard treatment of choice is surgical resection. ${ }^{6-10}$ These tumours are not routinely offered postoperative adjuvant radiation therapy. Adjuvant radiation therapy or chemotherapy may have to be used for residual, recurrent disease or for palliation. ${ }^{4} 67$ In the case of the patient documented here, radiotherapy or chemotherapy was not given after operation.

Many surgical approaches have been reported in the literature: lateral rhinotomy approach, Weber-Ferguson approach, sublabial transnasal approach, Le Fort I down-fracture approach, anterior craniofacial approach and transnasal 

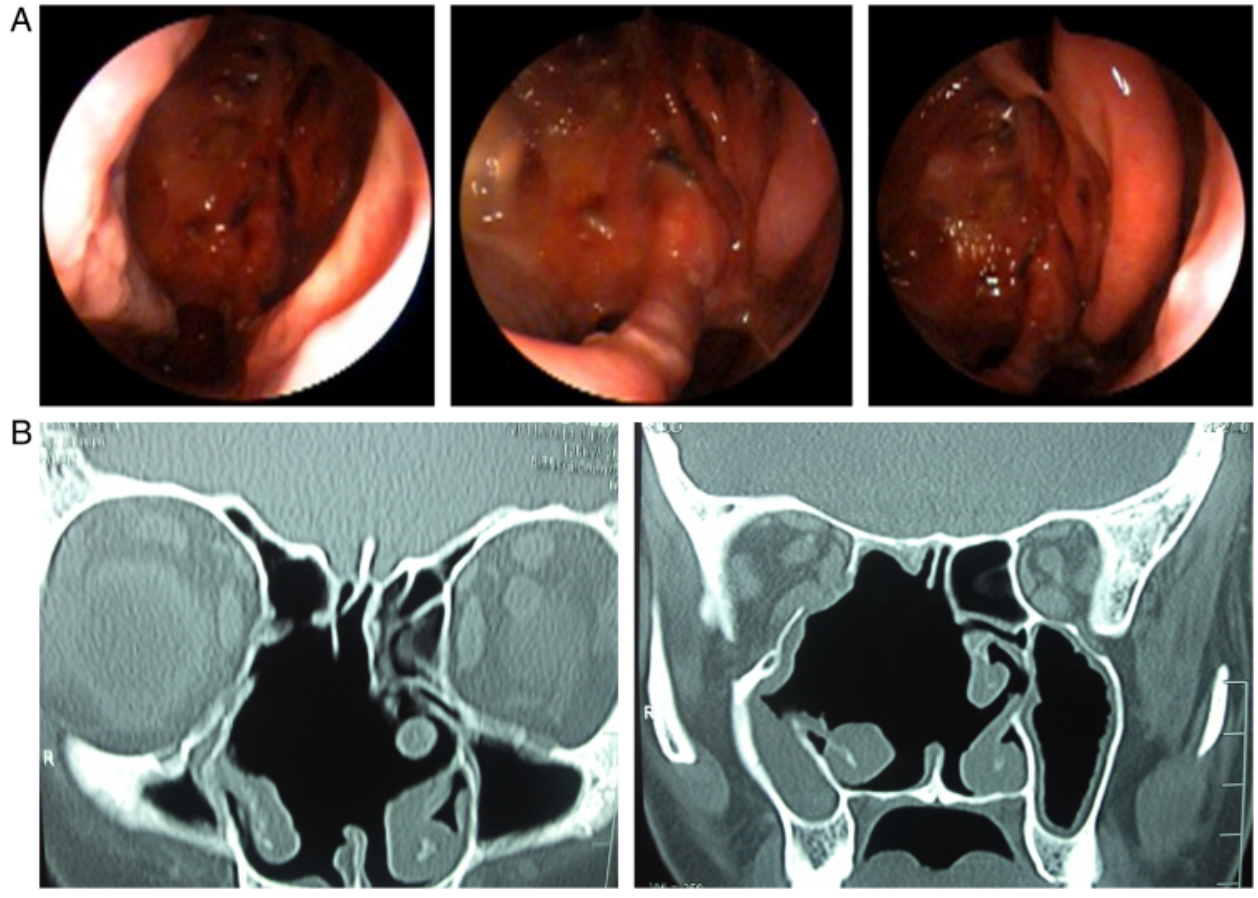

Figure 4 (A) Follow-up nasal endoscopy showing complete removal of the tumour with no evidence of recurrence. S, septum; MT, middle turbinate (arrow showing the area of the excised tumour). (B) Follow-up CT showing complete removal of the tumour with no evidence of recurrence (arrow showing the area of the excised tumour).

excision. The most common approach other than transnasal excision has been the lateral rhinotomy aproach. ${ }^{1-6}$ It was reported that nasal septal chondrosarcoma can be managed only by endoscopic surgery. ${ }^{7-9}$ The endoscopic approach has the advantages of being more cosmetic, of having a short operative time and a short hospital stay, and of allowing an early return to normal life compared to the external approach. ${ }^{7}$ Only tumours that are of limited size, fully visualised by endoscopic techniques without erosion of the skull base and no intracranial extension are amenable to endoscopic resection. ${ }^{7-10}$ So not all cases can be treated by endoscopic approach because of the risk of surgical complications, especially leakage of cerebrospinal fluid at removal of the tumour from the skull base. A reported case used a navigation system in endoscopic surgery without complications by means of a midfacial degloving approach at primary operation and an external incision approach at salvage operation for local recurrence. ${ }^{9}$

The external incision approach can be used in large invasive tumours with skull base erosion to obtain wide good vision and complete resection with a histologically clear safety margin. ${ }^{1-4610}$ In the literature, there is a case reported with significant intracranial extension that required surgical repair of the anterior fossa floor. ${ }^{11}$ The repair was made using a split-calvaria osteoplastic rotational flap. This method provided structural integrity while avoiding the risks associated with the use of free bone grafts and metallic meshes. ${ }^{11}$

Regular follow-up by nasal endoscopy is mandatory to detect any recurrences. ${ }^{679}$ Our patient remained free of disease at 1-year follow-up.

The prognosis depends on the location and extent of the lesion, adequacy of treatment and degree of differentiation. 6 Patients with incomplete resections requiring further radiotherapy or chemotherapy have a bad prognosis.
Generally, the posterior nasal cavity and nasopharynx are the sites with poor prognosis because of late presentation. ${ }^{6}$

\section{Learning points}

- Chondrosarcoma of the nasal septum is a rare malignancy. When it occurs, early diagnosis is difficult because patients generally present with common, non-specific sinonasal complaints. Usually nasal obstruction, headache, facial pain, anosmia and ear fullness are presenting symptoms.

- Both CT and MRI are needed to fully evaluate the bone and soft-tissue characteristics of the lesion.

- The diagnosis of chondrosarcomas is made by biopsy and histopathological examination.

- Chondrosarcoma is a radio-resistant tumour. The treatment of choice is surgical resection.

Chondrosarcoma can be surgically excised endoscopically or by an external approach. Only limited-size tumours that are fully visualised by an endoscopic approach without skull-base erosions or intracranial extension can be removed endoscopically. Regular follow-up is mandatory. Adjuvant radiotherapy or chemotherapy may have to be used for residual, recurrent disease or for palliation.

- The prognosis depends on the location and extent of the lesion and degree of differentiation. Generally, the posterior nasal cavity and nasopharynx are the sites with poor prognosis because of late presentation.

\section{Competing interests None.}

Patient consent Obtained. 


\section{BMJ Case Reports}

\section{REFERENCES}

1. Downey TJ, Clark SK, Moore DW. Chondrosarcoma of the nasal septum. Otolaryngol Head Neck Surg 2001;125:98-100.

2. Rassekh CH, Nuss DW, Kapadia SB, et al. Chondrosarcoma of the nasa septum: skull base imaging and clinicopathologic correlation. Otolaryngol Head Neck Surg 1996;115:29-37.

3. Bulut $\mathbf{F}$, Kizilay A, Aydin NE. Chondrosarcoma of the nasal septum: a case report. Kulak Burun Bogaz Ihtis Derg 2004;12:39-41.

4. Coppit GL, Eusterman VD, Bartels J, et al. Endoscopic resection of chondrosarcomas of the nasal septum: a report of 2 cases. Otolaryngol Head Neck Surg 2002;127:569-71.

5. Yamamoto S, Motoori K, Takano H, et al. Chondrosarcoma of the nasal septum. Skeletal Radiol 2002;31:543-6.
6. Ali A, Gosavi M, Michael R, et al. Chondrosarcoma of the nasal septum. Indian J Otolaryngol Head Neck Surg 2004;56:314-16.

7. Carrau RL, Aydogan B, Hunt JL. Chondrosarcoma of the sphenoid sinus resected by an endoscopic approach. Am J Otolaryngol 2004;25:274-7.

8. Jenny L, Harvinder S, Gurdeep $S$, et al. Endoscopic resection of primary nasoseptal chondrosarcoma. Med J Malaysia 2008;63:335-6.

9. Kainuma K, Netsu K, Asamura K, et al. Chondrosarcoma of the nasal septum: a case report. Auris Nasus Larynx 2009;36:601-5.

10. Rahal A, Durio JR, Hinni ML. Chondrosarcoma of the nasal septum. Ear Nose Throat J 2009;88:744-5.

11. Spear S, Iskandar J, Seaquist D, et al. Nasoseptal chondrosarcoma resection requiring anterior fossa floor repair: a case report. Ear Nose Throat $J$ 2008;87:696-9.

This pdf has been created automatically from the final edited text and images.

Copyright 2012 BMJ Publishing Group. All rights reserved. For permission to reuse any of this content visit http://group.bmj.com/group/rights-licensing/permissions.

BMJ Case Report Fellows may re-use this article for personal use and teaching without any further permission.

Please cite this article as follows (you will need to access the article online to obtain the date of publication).

Bahgat M, Bahgat Y, Bahgat A, Elwany Y. Chondrosarcoma of the nasal septum. BMJ Case Reports 2012;10.1136/bcr-2012-006266, Published XXX

Become a Fellow of BMJ Case Reports today and you can:

- Submit as many cases as you like

- Enjoy fast sympathetic peer review and rapid publication of accepted articles

- Access all the published articles

- Re-use any of the published material for personal use and teaching without further permission

For information on Institutional Fellowships contact consortiasales@bmjgroup.com

Visit casereports.bmj.com for more articles like this and to become a Fellow 